\title{
Crucial IncRNAs associated with adipocyte differentiation from human adipose-derived stem cells based on co-expression and ceRNA network analyses
}

\author{
Kana Chen $^{1}$, Shujie Xie ${ }^{2}$, Wujun Jin ${ }^{\text {Corresp. } 1}$ \\ 1 Department of Plastic Surgery, Hwa Mei Hospital, University of Chinese Academy of Sciences, Ningbo, Zhejiang, China \\ 2 Department of Hepatobiliary Surgery, Hwa Mei Hospital, University of Chinese Academy of Sciences, Ningbo, Zhejiang, China \\ Corresponding Author: Wujun Jin \\ Email address: wujunjin2019@163.com
}

Background: Injection of adipose derived stem cells (ASCs) is a promising treatment for facial contour deformities. However, its treatment mechanisms remain largely unknown. The study aimed to explain the molecular mechanisms of adipogenic differentiation from ASCs based on the roles of long noncoding RNAs (IncRNAs).

Methods: Datasets of mRNA-IncRNA (GSE113253) and miRNA (GSE72429) expression profiling were collected from Gene Expression Omnibus database. The differentially expressed genes (DEGs), IncRNAs (DELs) and miRNAs (DEMs) between undifferentiated and adipocyte differentiated human ASCs were identified using the LIMMA method. DELs related co-expression and competing endogenous RNA (ceRNA) networks were constructed. Protein-protein interaction (PPI) analysis was performed to screen crucial target genes.

Results: A total of 748 DEGs, 17 DELs and 51 DEMs were identified. Thirteen DELs and 279 DEGs with Pearson correlation coefficients $>0.9$ and $p$-value $<0.01$ were selected to construct the co-expression network. A total of 151 interaction pairs among 112 nodes (10 DEMs; 8 DELs; 94 DEGs) were obtained to construct the ceRNA network. By comparing the IncRNAs and mRNAs in two networks, five IncRNAs (SNHG9, LINC02202, UBAC2-AS1, PTCSC3 and MIAT) and 32 genes (i.e. such as PIK3R1, PTPRB) were found to be shared. PPI analysis demonstrated PIK3R1, FOXO1 (a transcription factor), and ESR1 were hub genes, which could be regulated by the miRNAs that interacted with the above five IncRNAs, such as LINC02202-miR-136-5p-PIK3R1, LINC02202-miR-381-3p-FOXO1 and MIAT-miR-18a-5p-ESR1. LINC02202 also could directly co-express with PIK3R1. Furthermore, PTPRB was predicted to be modulated by coexpression with LINC01119.

Conclusion: MIAT, LINC02202 and LINC01119 may be potentially important, new IncRNAs associated with adipogenic differentiation of ASCs. They may be involved in adipogenesis by acting as a ceRNA or co-expressing with their targets. 
1 Crucial IncRNAs associated with adipocyte differentiation from human adipose-derived

2 stem cells based on co-expression and ceRNA network analyses

3

4

\section{Kana Chen ${ }^{1}$, Shujie Xie ${ }^{2}$, Wujun Jin ${ }^{1 *}$}

$5{ }^{1}$ Department of Plastic Surgery, Hwa Mei Hospital, University of Chinese Academy of Sciences,

6 Ningbo, Zhejiang, 315010, China;

7 2Department of Hepatobiliary Surgery, Hwa Mei Hospital, University of Chinese Academy of

8 Sciences, Ningbo, Zhejiang, 315010, China.

$10 *$ Corresponding author: Wujun Jin.

11 Email: wujunjin2019@163.com; Telephone:+86-13780088664.

12 Corresponding address: Department of Plastic Surgery, Hwa Mei Hospital, University of 13 Chinese Academy of Sciences, Haishu District, No.41 Northwest Street, Ningbo, Zhejiang, 14 315010, China. 


\section{Abstract}

Background: Injection of adipose derived stem cells (ASCs) is a promising treatment for facial contour deformities. However, its treatment mechanisms remain largely unknown. The study aimed to explain the molecular mechanisms of adipogenic differentiation from ASCs based on the roles of long noncoding RNAs (lncRNAs).

Methods: Datasets of mRNA-lncRNA (GSE113253) and miRNA (GSE72429) expression profiling were collected from Gene Expression Omnibus database. The differentially expressed genes (DEGs), lncRNAs (DELs) and miRNAs (DEMs) between undifferentiated and adipocyte differentiated human ASCs were identified using the LIMMA method. DELs related coexpression and competing endogenous RNA (ceRNA) networks were constructed. Proteinprotein interaction (PPI) analysis was performed to screen crucial target genes.

Results: A total of 748 DEGs, 17 DELs and 51 DEMs were identified. Thirteen DELs and 279 DEGs with Pearson correlation coefficients $>0.9$ and p-value $<0.01$ were selected to construct the co-expression network. A total of 151 interaction pairs among 112 nodes (10 DEMs; 8 DELs; 94 DEGs) were obtained to construct the ceRNA network. By comparing the lncRNAs and mRNAs in two networks, five lncRNAs (SNHG9, LINC02202, UBAC2-AS1, PTCSC3 and MIAT) and 32 genes (i.e. such as PIK3R1, PTPRB) were found to be shared. PPI analysis demonstrated PIK3R1, FOXO1 (a transcription factor), and ESR1 were hub genes, which could be regulated by the miRNAs that interacted with the above five lncRNAs, such as LINC02202miR-136-5p-PIK3R1， LINC02202-miR-381-3p-FOXO1 and MIAT-miR-18a-5p-ESR1. LINC02202 also could directly co-express with PIK3R1. Furthermore, PTPRB was predicted to be modulated by co-expression with LINC01119.

Conclusion: MIAT, LINC02202 and LINC01119 may be potentially important, new lncRNAs 
54 acting as a ceRNA or co-expressing with their targets.

55 Key words: Human adipose tissue-derived stromal stem cells; adipogenic differentiation; 56 ceRNA; lncRNA; miRNA; co-expression

57 Introduction

Autologous adipose tissue grafting has been a widely accepted surgical tool for anti-aging cosmetics (Charles-de-Sá L 2015) and reconstructive restoration of various congenital or acquired facial soft tissue deformities (Bashir et al. 2018). However, conventional fat grafting 61 procedure needs to be repeated multiple times to achieve satisfactory results (Bashir et al. 2018), which may be associated with the low graft survival rate and poor revascularization (Ma L 2015). To overcome these two limitations, recent scholars propose to combine with additional autologous adipose-derived stem cells (ASCs) which have the ability to differentiate into mature adipocytes to supplement apoptotic cells and secrete angiogenic growth factors to enhance angiogenesis (Bashir et al. 2018; Kotaro et al. 2008; Philips et al. 2014). The clinical trials also confirm that supplementation of ASCs to adipose grafts is superior to conventional lipoinjection for facial recontouring (Bashir et al. 2018; Kotaro et al. 2008). Nevertheless, the use of autologous ASCs has not been FDA-approved. This may be because there still remains a huge gap in understanding the potential mechanisms of ASCs for adipocyte differentiation.

Increasing evidence has suggested long noncoding RNAs (lncRNAs), a class of noncoding RNAs more than 200 nucleotides, play crucial roles in adipogenesis for ASCs. For example, Nuermaimaiti et al. demonstrated that knockdown of HOXA11-AS1 inhibited adipocyte differentiation, leading to suppression of adipogenic-related gene transcription, as well as decreased lipid accumulation in ASCs (Nuermaimaiti et al. 2018). Huang et al. observed knockdown of MIR31HG inhibited adipocyte differentiation, whereas overexpression of MIR31HG promoted adipogenesis in vitro and in vivo (Huang et al. 2017). MEG3 was also found to be downregulated during adipogenesis of ASCs. Functional analysis showed that knockdown of MEG3 promoted adipogenic differentiation of ASCs (Zheng et al. 2017).

80 Furthermore, current research shows lncRNAs, on one hand, functions as microRNA (miRNAs) 
81 sponges to bind the miRNA response elements (MREs) and regulate miRNA-mediated gene 82 silencing [that is, competing endogenous RNA (ceRNA) hypothesis]; and, on the other hand, 83 directly influences their neighboring genes expression by chromatin remodeling or 84 transcriptional control (co-expression model)(Huang et al. 2016; Li et al. 2017). These theories 85 have also been reported in ASCs. Li et al. proved downregulated MEG3 may be insufficient to 86 sponge miR-140-5p and lead to its upregulation during adipogenesis in ASCs (Zheng et al. 2017). 87 The study of Huang et al. revealed inhibition of MIR31HG reduced the enrichment of active 88 histone markers, histone H3 lysine 4 trimethylation and acetylation, in the promoter of fatty acid 89 binding protein 4, resulting in suppression of its expression and adipogenesis (Huang et al. 2017). 90 However, the adipogenic differentiation related lncRNAs and its mechanisms of ASCs remains 91 rarely reported.

92 The present study aimed to identify crucial lncRNAs involved in adipocyte differentiation of 93 ASCs by constructing lncRNA-miRNA-mRNA ceRNA network and lncRNA-mRNA co94 expression network using high throughput analysis data. Our findings might offer greater 95 insights into the molecular mechanisms of adipocyte differentiation from ASCs and provide 96 potentially new targets for inducing adipogenesis.

\section{Materials and methods}

\section{Collection of microarray data}

99 GSE113253 (Rauch et al. 2019) and GSE72429 datasets (Supplemental Information 1) were 100 downloaded from the Gene Expression Omnibus (GEO) database 101 (http://www.ncbi.nlm.nih.gov/geo/). GSE113253 dataset applied the high throughput sequencing 102 methodology to simultaneously detect the lncRNA and mRNA expression profiles in 2 repeats of

103 undifferentiated human ASCs and 10 repeats of adipogenic differentiation cells using an Illumina 104 HiSeq 1500 instrument, which was submitted to GEO on Apr 17, 2018. GSE72429 dataset 105 analyzed the miRNA expression profile in 4 undifferentiated human ASCs and 2 adipogenic 106 differentiation cells using an Agilent-031181 Unrestricted_Human_miRNA_V16.0_Microarray 107 (miRBase release 16.0 miRNA ID version), which was submitted to GEO on Aug 27, 2015. 
108

109

110

111 lncRNAs and mRNAs in GSE113253 were obtained. The differentially expressed genes (DEGs),

$112 \operatorname{lncRNAs}(\mathrm{DELs})$ and miRNAs (DEMs) were identified using the Linear Models for Microarray

113 Data (LIMMA)

software

(version

3.34.0;

114 https://bioconductor.org/packages/release/bioc/html/limma.html). P-value was adjusted by using

115 Benjamini-Hochberg method to avoid false positives. The heatmap was constructed to present

116 the expression difference of DEGs, DELs and DEMs in different samples using the pheatmap

117 package (version: 1.0.8; https://cran.r-project.org/web/packages/pheatmap) based on Euclidean

118 distance.

\section{Co-expression network between IncRNA and mRNA}

120 The co-expression network was constructed based on the correlation analysis between

121 DELs and DEGs. Pearson correlation coefficients were calculated using the WGCNA (Weighted

122 Gene

Correlation

Network

Analysis;

123 https://horvath.genetics.ucla.edu/html/CoexpressionNetwork/Rpackages/WGCNA/Tutorials/)

124 algorithm to assess the correlation. Only the co-expressed pairs with absolute value of Pearson correlation coefficients $\geq 0.9$ and $\mathrm{p}<0.01$ were selected to draw the network using Cytoscape

126 (version 3.4; www.cytoscape.org/) (Kohl et al. 2011).

\section{CeRNA regulatory network among DELs, DEMs and DEGs}

128 The DEMs related target genes were predicted using the miRwalk database (version 2.0; http: 129 //www.zmf.umm.uni-heidelberg.de/apps/zmf/mirwalk2) (Dweep \& Gretz 2015) which provides

13012 prediction algorithms (miRWalk, MicroT4, miRanda, miRBridge, miRDB, miRMap,

131 miRNAMap, PICTAR2, PITA, RNA22, RNAhybrid, Targetscan). Only the miRNA-target gene

132 interaction pairs that were predicted in at least 8 databases were used. The target genes were then

133 overlapped with the DEGs to screen negatively correlated DEM-DEG interaction pairs. The

134 miRcode (http://www.mircode.org/)(Ashwini et al. 2012), starBase (version 2.0; 
135 http://starbase.sysu.edu.cn/starbase2/) (Li et al. 2014) and DIANA-LncBase (version 2.0;

136 http://carolina.imis.athena-innovation.gr/diana_tools/web/index.php?r=lncbasev2/index-

137 predicted)(Paraskevopoulou et al. 2013) databases were used to predict the interaction

138 relationship between DELs and DEMs. The negatively correlated DEL-DEM interaction pairs

139 were left for further analysis. The DEL-DEM and DEM-DEG interactors were integrated to

140 construct the ceRNA network, which was visualized using Cytoscape.

\section{Protein-protein interaction (PPI) network}

142 PPI data of DEGs in the ceRNA network was collected from STRING (Search Tool for the

143 Retrieval of Interacting Genes; version 10.0; http://string db.org/) database (Szklarczyk et al.

144 2015). Only interactions with combined score $>0.4$ were selected to construct the PPI network.

145 Several topological features of the nodes (protein) in the PPI network were calculated using the

146 CytoNCA plugin in cytoscape software (http://apps.cytoscape.org/apps/cytonca) (Tang et al.

147 2015) to screen hub genes, including degree, eigenvector, betweenness and closeness centrality.

148 Furthermore, transcription factors were predicted using iRegulon (Janky et al. 2014) in

149 Cytoscape and then integrated to the PPI network.

\section{Function enrichment analysis}

151 Gene ontology (GO) and Kyoto Encyclopedia of Genes and Genomes (KEGG) pathway 152 enrichment analyses were performed using the Database for Annotation, Visualization and 153 Integrated Discovery (DAVID) online tool (version 6.8; http://david.abcc.ncifcrf.gov) (Huang et 154 al. 2009) to reveal the function of DEGs. $\mathrm{P}<0.05$ was set as the cut-off value.

\section{Results}

\section{Differential expression analysis}

157 Due to the fact that fewer DEGs, DELs and DEMs were identified if adjusted p-value was 158 defined as the statistical threshold; therefore, genes, lncRNAs and miRNAs were believed to be 159 differentially expressed in this study when their $\mid \log 2$ fold change (FC)| was more than 1 and p160 value was less than 0.05 . Based on these given thresholds, a total of 748 protein-coding genes

161 (360, upregulated; 388, downregulated)(Table 1;Supplemental Information 2) and 17 lncRNAs 
162 (9, upregulated; 8, downregulated) (Table 1; Supplemental Information 2) were found to be

163 differentially expressed in adipogenic differentiation cells compared with undifferentiated cells

164 in GSE113253 dataset. Among them, 121 DEGs [such as FOXO1 (forkhead box O1), PTPRB

165 (protein tyrosine phosphatase receptor type B)] and 2 DELs (SH3RF3-AS1, LINC01119) had

166 adjusted $\mathrm{p}$-value $<0.05$, indicating they were especially crucial for adipogenic differentiation. A

167 total of 51 miRNAs (Table 1; Supplemental Information 2) were identified to be significantly

168 differentially expressed in GSE72429 within the $\mathrm{p}<0.05$ and $|\log 2 \mathrm{FC}|>1$ criteria. Among them,

16920 DEMs (particularly, miR-663 and miR-3607-3p, with adjusted p-value $<0.05$ ) were

170 upregulated and 31 DEMs (particularly, miR-150*, miR-4271, miR-371-5p and miR-134, with

171 adjusted p-value < 0.05) were downregulated. Additionally, hierarchical clustering of DEGs

172 (Figure 1A), DELs (Figure 1B) and DEMs (Figure 1C) expression levels indicated the

173 differentiated samples could be well distinguished from the undifferentiated samples.

174 Construction of co-expression and ceRNA networks

175 A total of 13 DELs and 279 DEGs with Pearson correlation coefficients $>0.9$ and p-value $<$

1760.01 were selected to construct the lncRNA-mRNA co-expression network, which contained 440

177 positive connections (Figure 2; Supplemental Information 3).

178 Based on at least 8 database analyses in miRwalk 2.0 and negatively correlated principles, a 179 total of 79 downregulated DEGs were predicted to be regulated by 8 upregulated DEMs, while

180128 upregulated DEGs were predicted to be regulated by 32 downregulated DEMs. Using the 181 starBase database, 355 miRNAs were predicted to interact with 25 DELs; using the miRcode 182 database, 192 miRNAs were predicted to interact with 8 DELs; using the DIANA-LncBase 183 database, 1343 miRNAs were predicted to interact with 15 DELs. After overlapping the DEMs

184 that interacted with DELs and DEMs that regulated DEGs, 151 interaction pairs among 112 185 nodes (10 DEMs, 4 upregulated and 6 downregulated; 8 DELs, 4 upregulated and 4 186 downregulated; 94 DEGs, 46 upregulated and 48 downregulated) were obtained, which were 187 used for constructing the ceRNA network (Figure 3; Supplemental Information 4).

\section{PPI network}


189 PPI pairs were predicted for the 94 DEGs in the ceRNA network using the STRING 190 database, which resulted in 80 interaction relationship pairs that were screened between 58 nodes

191 (24 upregulated and 34 downregulated) (Figure 4). PIK3R1 (phosphoinositide-3-kinase

192 regulatory subunit 1), FYN (FYN proto-oncogene, Src family tyrosine kinase) and ESR1

193 (estrogen receptor 1) were considered as hub genes in the PPI network because they ranked the 194 top 10 in all four topological features (Table 2). In addition, FOXO1, which was included in the

195 PPI network, was predicted as a differentially expressed transcription factor to regulate the other

196 target genes in the PPI network using IRegulon plug-in (Figure 4), indicating FOXO1 was also a 197 hub gene.

198 Function analysis showed 8 significant KEGG pathways were enriched, including 199 hsa04015:Rap1 signaling pathway (PIK3R1), hsa05200:Pathways in cancer (PIK3R1, FOXO1), 200 hsa05205:Proteoglycans in cancer (ESR1, PIK3R1), hsa04014:Ras signaling pathway (PIK3R1), 201 hsa05218:Melanoma (PIK3R1) and hsa04520:Adherens junction (PTPRB) (Table 3).

202 In addition, 79 GO biological process terms were also enriched, such as 203 GO:0042981 regulation of apoptotic process (ESR1), GO:0045893 positive regulation of 204 transcription, DNA-templated (ESR1, FOXO1), GO:0043066 negative regulation of apoptotic 205 process (FOXO1, PIK3R1), GO:0014066 regulation of phosphatidylinositol 3-kinase signaling 206 (PIK3R1), GO:0048146 positive regulation of fibroblast proliferation (ESR1), 207 GO:0001525 angiogenesis (PTPRB) and GO:0001678 cellular glucose homeostasis (FOXO1, 208 PIK3R1) (Table 4; Supplemental Information 5).

209 Integrated analysis to identify crucial IncRNAs

210 By comparing the co-expression with ceRNA networks, five lncRNAs (SNHG9, 211 LINC02202, UBAC2-AS1, PTCSC3 and MIAT) and 32 genes (such as PIK3R1, PTPRB) were 212 found to be shared.

213 By comparing the hub genes enriched into KEGG pathways with the genes regulated by the 214 above five lncRNAs (SNHG9, LINC02202, UBAC2-AS1, PTCSC3 and MIAT), we found the 215 following ceRNA and co-expression axes may be important, including LINC02202 
216 (upregulated)-hsa-miR-136-5p (downregulated)-PIK3R1 (upregulated), LINC02202

217 (upregulated)-hsa-miR-381-3p (downregulated)-FOXO1 (upregulated), MIAT (downregulated)-

218 hsa-miR-18a-5p (upregulated)-ESR1 (downregulated) and LINC02202 (downregulated)-

219 PIK3R1(downregulated). Furthermore, the comparison between hub genes enriched into KEGG

220 pathways and the shared genes in two networks also indicated PTPRB related co-expression axis

221 [(LINC01119 (downregulated)-PTPRB (downregulated)] was also crucial.

\section{Discussion}

223 In present study, we identified three crucial lncRNAs (MIAT, LINC02202, and LINC01119)

224 for adipogenesis from human ASCs. MIAT may sponge hsa-miR-18a-5p and influence the 225 inhibition of hsa-miR-18a-5p on the expression of ESR1. LINC02202 may function as a ceRNA

226 for hsa-miR-136-5p/hsa-miR-381-3p to respectively regulate the expressions of PIK3R1 and 227 FOXO1; LINC02202 also may directly affect the transcription of PIK3R1. LINC01119 may co228 express with PTPRB to impact its transcription. Although all these relationship pairs may be 229 potentially important, LINC01119-PTPRB co-expression axis may be especially verifiable 230 because their expression significance met the criterion of adjusted p-value $<0.05$.

231 Although there have studies to show the roles of lncRNA myocardial infarction associated 232 transcript (MIAT) for stem differentiation, only osteogenic (Jin et al. 2017) and endothelial cell 233 (Wang et al. 2018) differentiation were investigated, without evidence to prove its effect on 234 adipogenesis of human ASCs. A recent study revealed MIAT was an estrogen-inducible lncRNA 235 and its expression was positively related to estrogen receptor ( $\mathrm{Li}$ et al. 2018b). There was 236 accumulating evidence to reveal that exposure of bone marrow stem cells to icariin or flavonoids 237 of Herba Epimedii inhibited adipogenic differentiation, exhibiting decreased adipocyte numbers 238 and downregulated mRNA expression of adipogenic differentiation markers, peroxisome 239 proliferator-activated receptor gamma (PPAR $\gamma)$ and CCAAT/enhancer-binding protein $\alpha$ $240(\mathrm{C} / \mathrm{EBP} \alpha)(\mathrm{Li} X \mathrm{X} 2018$; Zhang et al. 2015); while treatment of bone marrow stem cells with 241 estrogen receptor antagonist ICI182780 revered the effects of Herba Epimedii ingredient and 242 promoted adipogenesis ( $\mathrm{Li}$ X 2018; Zhang et al. 2015). The study of Ihunnah et al. also 
243 demonstrated activation of estrogen receptor in ASCs inhibited adipogenesis by decreasing the

244 recruitment of the adipogenic PPAR $\gamma$ onto its target gene promoters, whereas the use of estrogen

245 receptor antagonism ICI 182780 or knockdown of estrogen receptor- $\alpha$ via lentiviral shRNA

246 enhanced adipogenesis by increasing the expression of PPAR $\gamma$ (Ihunnah et al. 2014). Thus, it can

247 be hypothesized that MIAT may be lower expressed in adipogenic differentiation cells like ESR1,

248 which was also confirmed in our study. However, the interaction mechanisms between MIAT

249 and estrogen receptor remain unclear. In present study, we predicted that downregulated MIAT

250 may be insufficient to sponge hsa-miR-18a-5p and lead to more hsa-miR-18a-5p to bind with the

2513 ' untranslated region (3'UTR) of ESR1, inducing the lower expression of ESR1. This hypothesis

252 may be indirectly demonstrated by the fact that miR-18a mimic significantly promoted MSC

253 adipogenic differentiation, while the addition of miR-18a inhibitor obtained the negative effects

254 on adipogenic differentiation of mesenchymal stem cells (MSCs) ( $\mathrm{Li}$ et al. 2018a). The negative

255 regulatory relationship between ESR1 and miR-18a were also validated in human trophoblast 256 cell line by the luciferase assay (Zhu et al. 2015).

257 LINC02202 may be a newly identified lncRNA associated with stem cell differentiation

258 because its role had not been previously mentioned in the literatures. In this study, we predicted

259 upregulated LINC02202 may be involved in ASCs adipogenic differentiation by regulating

260 phosphatidylinositol 3-kinase (PI3K) signaling. It has been reported that PI3K signaling pathway

261 was strongly activated in MSCs under the adipogenesis-inducing hormone cocktail (Kim et al.

262 2017), and the addition of PI3K specific inhibitor LY294002 severely suppressed lipid

263 accumulation, as well as the expression of adipogenic markers PPAR $\gamma$ and C/EBP $\alpha$ (Yu et al.

264 2008). PIK3R1 is a critical component of the PI3K signaling pathway and its expression was also

265 demonstrated to be increased after the induction of adipocyte differentiation from preadipocytes

266 3T3-L1 (Kim et al. 2014). Thus, theoretically, PIK3R1 may be upregulated in adipogenic

267 differentiation cells compared with undifferentiated human ASCs, which was confirmed in our

268 study. Activated PI3K/AKT signaling may promote adipogenesis through upregulating

269 downstream transcription factors, such as FoxO1 (Yi et al. 2018) which may subsequently 
270 enhance the transcription of its target genes, PPAR- $\gamma$ and C/EBP- $\alpha$ (Ambele et al. 2016;

271 Munekata \& Sakamoto 2009); whereas persistent inhibition of FoxO1 with its antagonist

272 AS1842856 (Zou et al. 2014) or knockdown of FoxO1 (Sun et al. 2017) was also observed to

273 almost completely suppress adipocyte differentiation and lipogenesis. As expected, we also

274 found FoxO1 was significantly high expressed during adipogenic differentiation. In addition to

275 directly affect the transcription of PIK3R1, LINC02202 may function as a ceRNA for miR-136-

$2765 \mathrm{p}$ and hsa-miR-381-3p to regulate the expression of PIK3R1a and FoxO1, respectively.

277 Although there was no study to demonstrate these ceRNA interaction axes, the negative

278 correlation between the expression of miR-136 and adipogenic markers C/EBP $\alpha$ and PPAR $\alpha$ in

279 subcutaneous adipose tissue of lambs may indirectly illuminate the importance of miR-136 for

280 adipogenic differentiation (Meale et al. 2014). As expected, we also found miR-136-5p was

281 significantly downregulated in adipogenic differentiation cells.

282 There was only one sequencing study to identify that LINC01119 was downregulated in 283 colorectal cancer cells after hypoxia treatment (Han et al. 2014). Several authors had 284 demonstrated hypoxia exposure was effective to enhance adipocyte differentiation from ASCs 285 (Fink et al. 2004; Valorani et al. 2012; Kim et al. 2013), which was medicated by the generation 286 of reactive oxygen species (ROS) and activation of PI3K/Akt/mTOR (Kim et al. 2014); the 287 addition of ROS scavenger or Akt/mTOR inhibitor prevented adipocyte differentiation (Kim et al. 288 2014). Thus, LINC01119 may have anti-adipose differentiation potential and lower expressed in 289 adipogenic differentiation cells compared with undifferentiated human ASCs, which was 290 validated in our study. However, its mechanisms for adipocyte differentiation remain unclear. 291 We predicted LINC01119 may co-express with PTPRB. The study of Kim et al. showed ectopic 292 over-expression of PTPRB inhibited the expression of adipocyte-related genes (such as PPAR- $\gamma$ ) 293 and led to a reduced adipocyte differentiation from preadipocytes. Also, PTPRB was reported to 294 suppress the tyrosine phosphorylation of VEGFR2 during adipocyte differentiation (Kim et al. 295 2019). Generally, VEGF functions by binding with VEGFR2, while transfection of VEGF to 296 ASCs increased fat cell survival (Zhang et al. 2017). These findings suggest PTPRB may also be 
297 downregulated to promote VEGF secretion and activate its mediated pathways, ultimately 298 inducing adipogenic differentiation from ASCs. This hypothesis was in line with our study

299 showing PTPRB was lower expressed in adipocyte differentiation cells and was involved in 300 angiogenesis.

301 There are some limitations in this study. First, only two datasets submitted within five years 302 until now, not all were used for this analysis, which may cause some bias in results due to the 303 small sample size and different data platforms. However, we believe the sequencing or 304 microarray technology may be more mature recently and thus the results may be more believable.

305 This was also indirectly reflected by the less overlapped genes if the other datasets were used 306 [only two comparing GSE72429 with GSE25715 (Guo et al. 2019)] and thus, we renounced the 307 use of multiple datasets and only the newly one. Moreover, this work investigated lncRNA co308 expression and ceRNA mechanisms, which required the lncRNA and mRNA should be 309 simultaneously analyzed. Thus, some datasets that only independently investigated lncRNA or 310 mRNA were also excluded. Second, the crucial co-expression and ceRNA axes were obtained by

311 database prediction, which may lead to many false positives. Therefore, further in vitro wet 312 experiments (PCR, luciferase assay, knockdown or overexpression) are still indispensable to 313 confirm the interaction between lncRNAs and miRNAs, lncRNA and mRNAs as well as the 314 miRNAs and mRNAs and their roles during adipogenic differentiation of ASCs.

\section{Conclusion}

316 The present study preliminarily identified three new targets (lncRNA MIAT, LINC02202 317 and LINC01119) for inducing of adipogenesis from human ASCs and promoting facial soft 318 tissue reconstruction. They may be involved in adipogenesis by acting as a ceRNA (LINC02202319 miR-136-5p-PIK3R1, LINC02202-miR-381-3p-FOXO1 and MIAT-miR-18a-5p-ESR1) or co320 expressing with its targets (LINC02202-PIK3R1, LINC01119-PTPRB).

321 Availability of data and materials

322 Raw data is available in Supplemental Materials (Supplemental Information 1).

\section{References}


324 Ambele MA, Dessels C, Durandt C, and Pepper MS. 2016. Genome-wide analysis of gene

325

326

327

328

329

330

331

332

333

334

335

336

337

338

339

340

341

342

343

344

345

346

347

348

349

350 expression during adipogenesis in human adipose-derived stromal cells reveals novel patterns of gene expression during adipocyte differentiation. Stem Cell Res 16:725-734.

Ashwini J, Marks DS, and Erik L. 2012. miRcode: a map of putative microRNA target sites in the long non-coding transcriptome. Bioinformatics 28:2062-2063.

Bashir MM, Sohail M, Bashir A, Khan FA, Jan SN, Imran M, Ahmad FJ, and Choudhery MS. 2018. Outcome of Conventional Adipose Tissue Grafting for Contour Deformities of Face and Role of Ex Vivo Expanded Adipose Tissue-Derived Stem Cells in Treatment of Such Deformities. J Craniofac Surg 29:1143-1147.

Charles-de-Sá L, Gontijo-de-Amorim NF, Maeda Takiya C, Borojevic R, Benati D, Bernardi P, Sbarbati A, Rigotti G. 2015. Antiaging treatment of the facial skin by fat graft and adipose-derived stem cells. Plast Reconstr Surg 135:999-1009.

Dweep H, and Gretz N. 2015. miRWalk2. 0: a comprehensive atlas of microRNA-target interactions. Nat Methods 12:697.

Fink T, Abildtrup L, Fogd K, Abdallah BM, Kassem M, Ebbesen P, Zachar V. 2004. Induction of adipocyte-like phenotype in human mesenchymal stem cells by hypoxia. Stem Cells 22:1346-1355.

Guo Z, Cao Y. 2019. An lncRNA-miRNA-mRNA ceRNA network for adipocyte differentiation from human adipose-derived stem cells. Mol Med Rep 19:4271-4287.

Han Y, Wang X, Mao E, Shen B, Huang L. 2019. Analysis of Differentially Expressed lncRNAs and mRNAs for the Identification of Hypoxia-Regulated Angiogenic Genes in Colorectal Cancer by RNA-Seq. Med Sci Monit 18;25:2009-2015.

Huang DW, Sherman BT, and Lempicki RA. 2009. Systematic and integrative analysis of large gene lists using DAVID bioinformatics resources. Nat Protoc 4:44-57.

Huang M, Zhong Z, Lv M, Shu J, Tian Q, and Chen J. 2016. Comprehensive analysis of differentially expressed profiles of lncRNAs and circRNAs with associated co-expression and ceRNA networks in bladder carcinoma. Oncotarget 7:47186-47200. 
351 Huang Y, Jin C, Zheng Y, Li X, Shan Z, Zhang Y, Jia L, and Li W. 2017. Knockdown of

352

353

354

355

356

357

358

359

360

361

362

363

364

365

366

367

368

369

370

371

372

373

374

375

376

377
lncRNA MIR31HG inhibits adipocyte differentiation of human adipose-derived stem cells via histone modification of FABP4. Sci Rep 7:8080.

Ihunnah CA, Wada T, Philips BJ, Ravuri SK, Gibbs RB, Kirisci L, Rubin JP, Marra KG, Xie W. 2014. Estrogen sulfotransferase/SULT1E1 promotes human adipogenesis. Mol Cell Biol $34: 1682-1694$.

Janky R, Verfaillie A, Imrichová H, Van de Sande B, Standaert L, Christiaens V, Hulselmans G, Herten K, Naval SM, and Potier D. 2014. iRegulon: from a gene list to a gene regulatory network using large motif and track collections. PLoS Comput Biol 10:e1003731.

Jin C, Zheng Y, Huang Y, Liu Y, Jia L, and Zhou Y. 2017. Long non-coding RNA MIAT knockdown promotes osteogenic differentiation of human adipose-derived stem cells. Cell Biol Int 41:33-41.

Kim J, Han D, Byun SH, Kwon M, Cho SJ, Koh YH, Yoon K. Neprilysin facilitates adipogenesis through potentiation of the phosphatidylinositol 3-kinase (PI3K) signaling pathway. Mol Cell Biochem 2017, 430(1-2):1-9.

Kim JH, Kim SH, Song SY, Kim WS, Song SU, Yi T, Jeon MS, Chung HM, Xia Y, Sung JH. 2014. Hypoxia induces adipocyte differentiation of adipose-derived stem cells by triggering reactive oxygen species generation. Cell Biol Int 38:32-40.

Kim JS, Kim WK, Oh KJ, Lee EW, Han BS, Lee SC, Bae KH. 2019. Protein Tyrosine Phosphatase, Receptor Type B (PTPRB) Inhibits Brown Adipocyte Differentiation through Regulation of VEGFR2 Phosphorylation. J Microbiol Biotechnol 29:645-650.

Kim YJ, Kim HJ, Chung KY, Choi I, Kim SH. 2014. Transcriptional activation of PIK3R1 by PPAR $\gamma$ in adipocytes. Mol Biol Rep 41:5267-5272.

Kohl M, Wiese S, and Warscheid B. 2011. Cytoscape: software for visualization and analysis of biological networks. Methods Mol Biol 696:291-303.

Kotaro Y, Katsujiro S, Noriyuki A, Masakazu K, Keita I, Hirotaka S, Hitomi E, Harunosuke K, Toshitsugu H, and Kiyonori H. 2008. Cell-assisted lipotransfer for facial lipoatrophy:

Peer] reviewing PDF | (2019:05:37581:1:1:NEW 10 Jul 2019) 
efficacy of clinical use of adipose-derived stem cells. Dermatol Surg 34:1178-1185.

379

380

381

382

383

384

385

386

387

388

389

390

391

392

393

394

395

396

397

398

399

400

401

402

403

404

Li JH, Liu S, Zhou H, Qu LH, and Yang JH. 2014. starBase v2.0: decoding miRNA-ceRNA, miRNA-ncRNA and protein-RNA interaction networks from large-scale CLIP-Seq data. Nucleic Acids Res 42:D92-97.

Li M, Xie Z, Wang P, Li J, Liu W, Tang SA, Liu Z, Wu X, Wu Y, and Shen H. 2018a. The long noncoding RNA GAS5 negatively regulates the adipogenic differentiation of MSCs by modulating the miR-18a/CTGF axis as a ceRNA. Cell Death Dis 9:554.

Li X, Ao J, and Wu J. 2017. Systematic identification and comparison of expressed profiles of lncRNAs and circRNAs with associated co-expression and ceRNA networks in mouse germline stem cells. Oncotarget 8:26573-26590.

Li X, Peng B, Pan Y, Wang P, Sun K, Lei X, Ou L, Wu Z, Liu X, Wang H, He H, Mo S, Tian Y, Peng X, Zhu X, Zhang R, Yang L. 2018. Icariin stimulates osteogenic differentiation and suppresses adipogenic differentiation of rBMSCs via estrogen receptor signaling. Mol Med Rep 18:3483-3489.

Li Y, Jiang B, Wu X, Huang Q, Chen W, Zhu H, Qu X, Xie L, Ma X, and Huang G. 2018 b. Long non-coding RNA MIAT is estrogen-responsive and promotes estrogen-induced proliferation in ER-positive breast cancer cells. Biochem Biophys Res Commun 503:4550.

Ma L, Wen H, Jian X, Liao H, Sui Y, Liu Y, Xu G. 2015. Cell-assisted lipotransfer in the clinical treatment of facial soft tissue deformity. Plast Surg 23:199-202.

Meale SJ, Romao JM, He ML, Chaves AV, Mcallister TA, and Guan LL. 2014. Effect of diet on microRNA expression in ovine subcutaneous and visceral adipose tissues. J Anim Sci 92:3328-3337.

Munekata K, and Sakamoto K. 2009. Forkhead transcription factor Foxol is essential for adipocyte differentiation. In Vitro Cell Dev Biol Anim 45:642-651.

Nuermaimaiti N, Liu J, Liang X, Jiao Y, Zhang D, Liu L, Meng X, and Guan Y. 2018. Effect of lncRNA HOXA11-AS1 on adipocyte differentiation in human adipose-derived stem cells. 
405

406

407

408

409

410

411

412

413

414

415

416

417

418

419

420

421

422

423

424

425

426

427

428

429

430

431

Biochem Biophys Res Commun 495:1878-1884.

Paraskevopoulou MD, Georgakilas G, Kostoulas N, Reczko M, Maragkakis M, Dalamagas TM, and Hatzigeorgiou AG. 2013. DIANA-LncBase: experimentally verified and computationally predicted microRNA targets on long non-coding RNAs. Nucleic Acids Res 41:D239-245.

Philips BJ, Marra KG, and Rubin JP. 2014. Healing of grafted adipose tissue: current clinical applications of adipose-derived stem cells for breast and face reconstruction. Wound Repair Regen 22:11-13.

Rauch A, Haakonsson AK, Madsen JGS, Larsen M, Forss I, Madsen MR, Van Hauwaert EL, Wiwie C, Jespersen NZ, Tencerova M, Nielsen R, Larsen BD, Röttger R, Baumbach J, Scheele C, Kassem M, Mandrup S. 2019. Osteogenesis depends on commissioning of a network of stem cell transcription factors that act as repressors of adipogenesis. Nat Genet 51:716-727.

Sun YM, Qin J, Liu SG, Cai R, Chen XC, Wang XM, and Pang WJ. 2017. PDGFR $\alpha$ Regulated by miR-34a and FoxO1 Promotes Adipogenesis in Porcine Intramuscular Preadipocytes through Erk Signaling Pathway. Int J Mol Sci 18:2424.

Szklarczyk D, Franceschini A, Wyder S, Forslund K, Heller D, Huerta-Cepas J, Simonovic M, Roth A, Santos A, and Tsafou KP. 2015. STRING v10: protein-protein interaction networks, integrated over the tree of life. Nucleic Acids Res 43:D447-452.

Tang Y, Li M, Wang J, Pan Y, and Wu FX. 2015. CytoNCA: a cytoscape plugin for centrality analysis and evaluation of protein interaction networks. Biosystems 127:67-72.

Valorani MG, Montelatici E, Germani A, Biddle A, D'Alessandro D, Strollo R, Patrizi MP, Lazzari L, Nye E, Otto WR, Pozzilli P, Alison MR. 2012. Pre-culturing human adipose tissue mesenchymal stem cells under hypoxia increases their adipogenic and osteogenic differentiation potentials. Cell Prolif 45:225-238.

Wang H, Ding XG, Yang JJ, Li SW, Zheng H, Gu CH, Jia ZK, and Li L. 2018. LncRNA MIAT facilitated BM-MSCs differentiation into endothelial cells and restored erectile 

97:180-189.

434

435

436

437

438

439

440

441

442

443

444

445

446

447

448

449

450

451

452

453

454

455

456

457

458

Yi L, Chen J, Tao X, Zhou Y, Yuan W, Wang M, Gan Y, Wang K, Xiong S, and Cong M. 2018. Epigallocatechin-3-gallate suppresses differentiation of adipocytes via regulating the phosphorylation of FOXO1 mediated by PI3K-AKT signaling in 3T3-L1 cells. Oncotarget 9:7411-7423.

Yu W, Chen Z, Zhang J, Zhang L, Ke H, Huang L, Peng Y, Zhang X, Li S, and Lahn BT. 2008. Critical role of phosphoinositide 3-kinase cascade in adipogenesis of human mesenchymal stem cells. Mol Cell Biochem 310:11-18.

Zhang D, Liu L, Jia Z, Yao X, and Yang M. 2015. Flavonoids of Herba Epimedii stimulate osteogenic differentiation and suppress adipogenic differentiation of primary mesenchymal stem cells via estrogen receptor pathway. Pharm Biol 54:954-963.

Zhang Y, Xiao LL, Li JX, Liu HW, Li SH, Wu YY, Liao X, Rao CQ. 2017. Improved fat transplantation survival by using the conditioned medium of vascular endothelial growth factor transfected human adipose-derived stem cells. Kaohsiung J Med Sci 33:379-384.

Zheng L, Jin C, Si C, Zheng Y, Huang Y, Jia L, Ge W, and Zhou Y. 2017. Long non-coding RNA MEG3 inhibits adipogenesis and promotes osteogenesis of human adipose-derived mesenchymal stem cells via miR-140-5p. Mol Cell Biochem 433:51-60.

Zhu X, Yang Y, Han T, Yin G, Gao P, Ni Y, Su X, Liu Y, and Yao Y. 2015. Suppression of microRNA-18a expression inhibits invasion and promotes apoptosis of human trophoblast cells by targeting the estrogen receptor $\alpha$ gene. Mol Med Rep 12:2701-2706.

Zou P, Liu L, Zheng L, Liu L, Stoneman RE, Cho A, Emery A, Gilbert ER, Cheng Z. 2014. Targeting FoxO1 with AS1842856 suppresses adipogenesis. Cell Cycle 13:3759-3767. 
484 Figure 1 Hierarchical clustering and heat map analysis of differentially expressed (A) genes, (B) 485 long non-coding RNAs and microRNAs (C). The color to red, high expression; the color to light 
486 blue, low expression.

487 Figure 2 Co-expression network between differentially expressed long non-coding RNAs and 488 genes. A, downregulated lncRNA-mRNA co-expression (blue); B, upregulated lncRNA-mRNA 489 co-expression (red). Circular, differentially expressed genes; rhombus, differentially expressed 490 long non-coding RNAs.

491 Figure 3 Competing endogenous RNA network (ceRNA) among differentially expressed long 492 non-coding RNAs, microRNAs and genes. A, downregulated ceRNA axes according to the 493 expression of miRNAs; B, upregulated ceRNA axes according to the expression of miRNAs. 494 Red, upregulated; Blue, downregulated. Circular, differentially expressed genes; rhombus, 495 differentially expressed long non-coding RNAs; triangle, microRNAs.

496 Figure 4 Protein-protein interaction network. Red, upregulated; Blue, downregulated. Oval, 497 differentially expressed genes; hexagon, differentially expressed transcription factor.

498

499 Supplemental Information 1: Raw data.

500 Supplemental Information 2: All differentially expressed genes.

501 Supplemental Information 3: LncRNA-mRNA co-expression pairs.

502 Supplemental Information 4: lncRNA-miRNA-mRNA interaction relationships.

503 Supplemental Information 5: GO enrichment results of PPI network genes. 
Figure 1

Hierarchical clustering and heat map analysis of differentially expressed (A) genes, (B) long non-coding RNAs and microRNAs (C). The color to red, high expression; the color to light blue, low expression. 
A

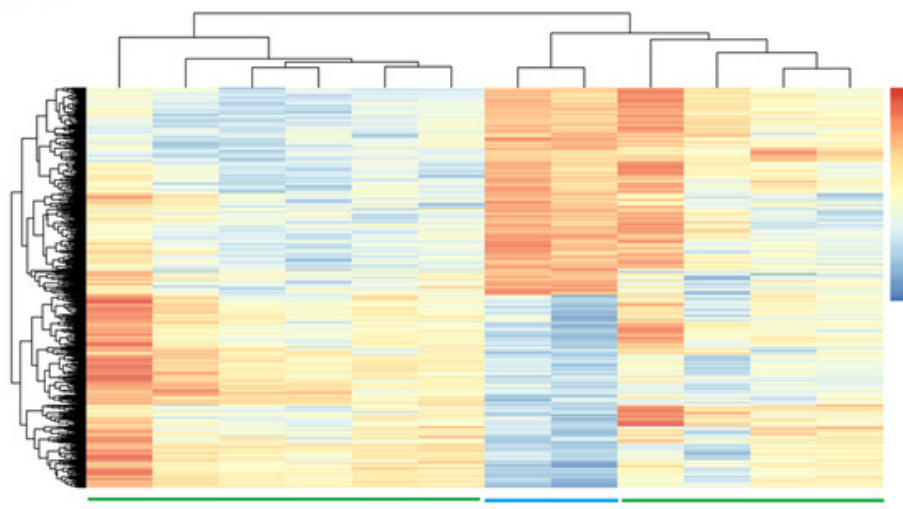

B

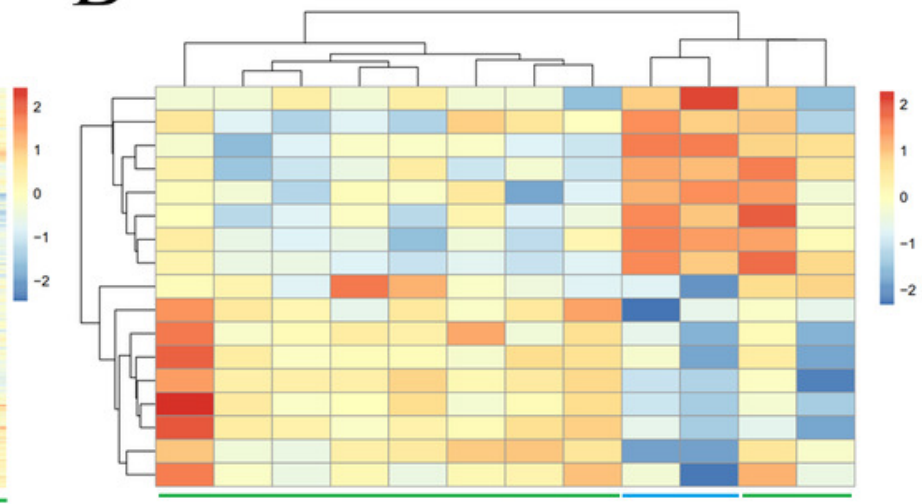

C

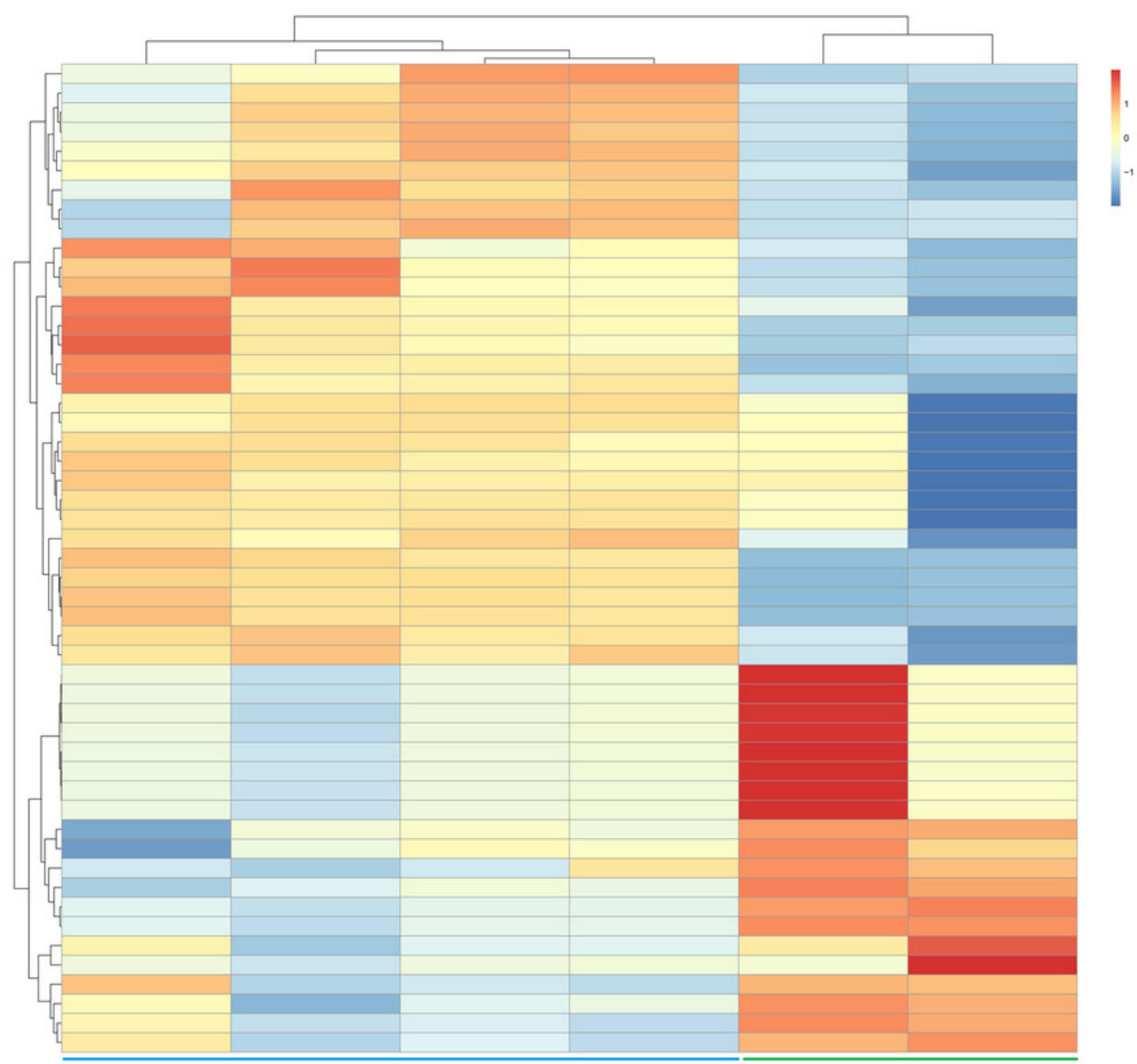


Figure 2

Co-expression network between differentially expressed long non-coding RNAs and genes

A, downregulated IncRNA-mRNA co-expression (blue); B, upregulated IncRNA-mRNA coexpression (red). Circular, differentially expressed genes; rhombus, differentially expressed long non-coding RNAs.
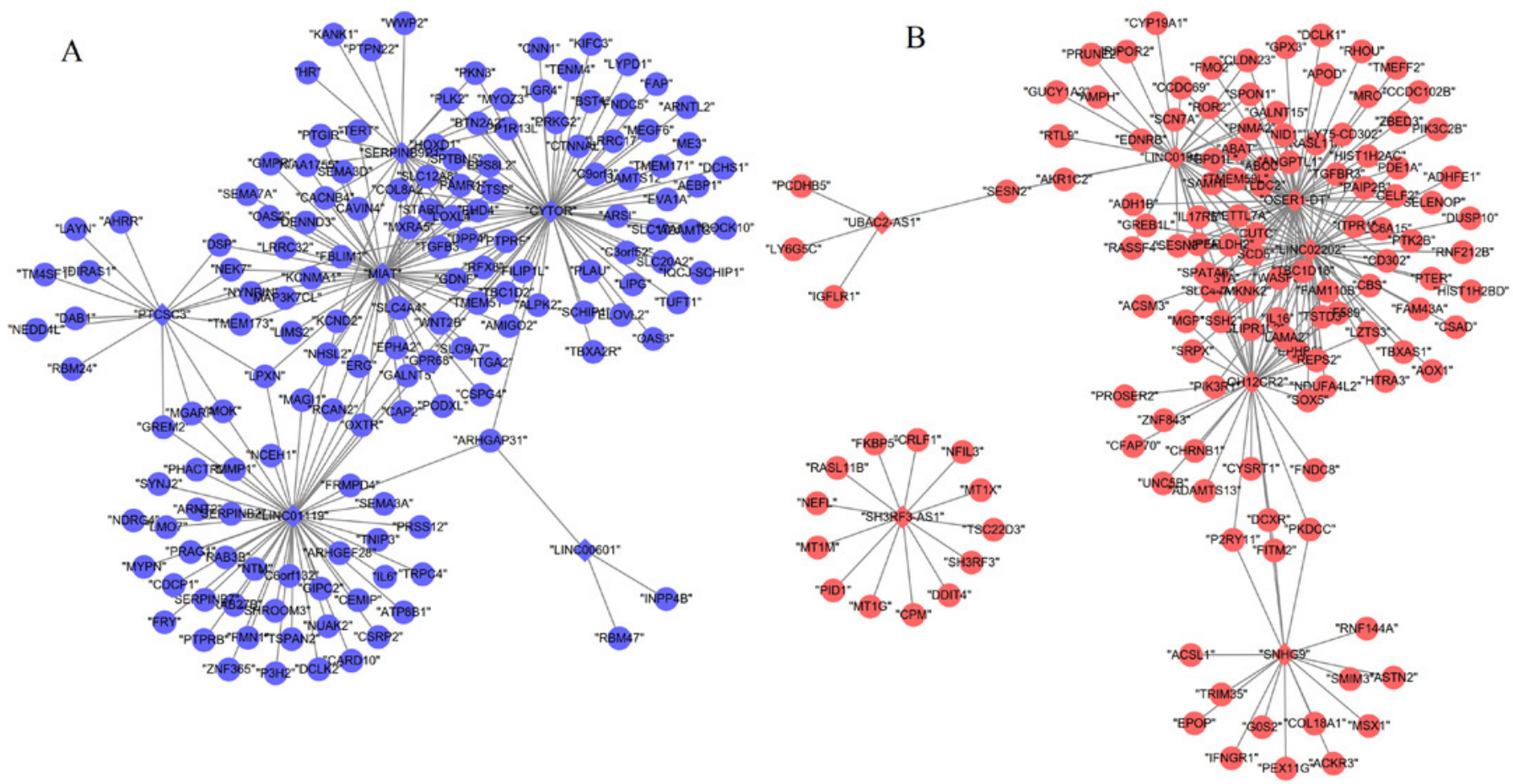
Figure 3

Competing endogenous RNA network (ceRNA) among differentially expressed long noncoding RNAs, microRNAs and genes.

A, downregulated ceRNA axes according to the expression of miRNAs; $B$, upregulated ceRNA axes according to the expression of miRNAs. Red, upregulated; Blue, downregulated.

Circular, differentially expressed genes; rhombus, differentially expressed long non-coding RNAs; triangle, microRNAs.
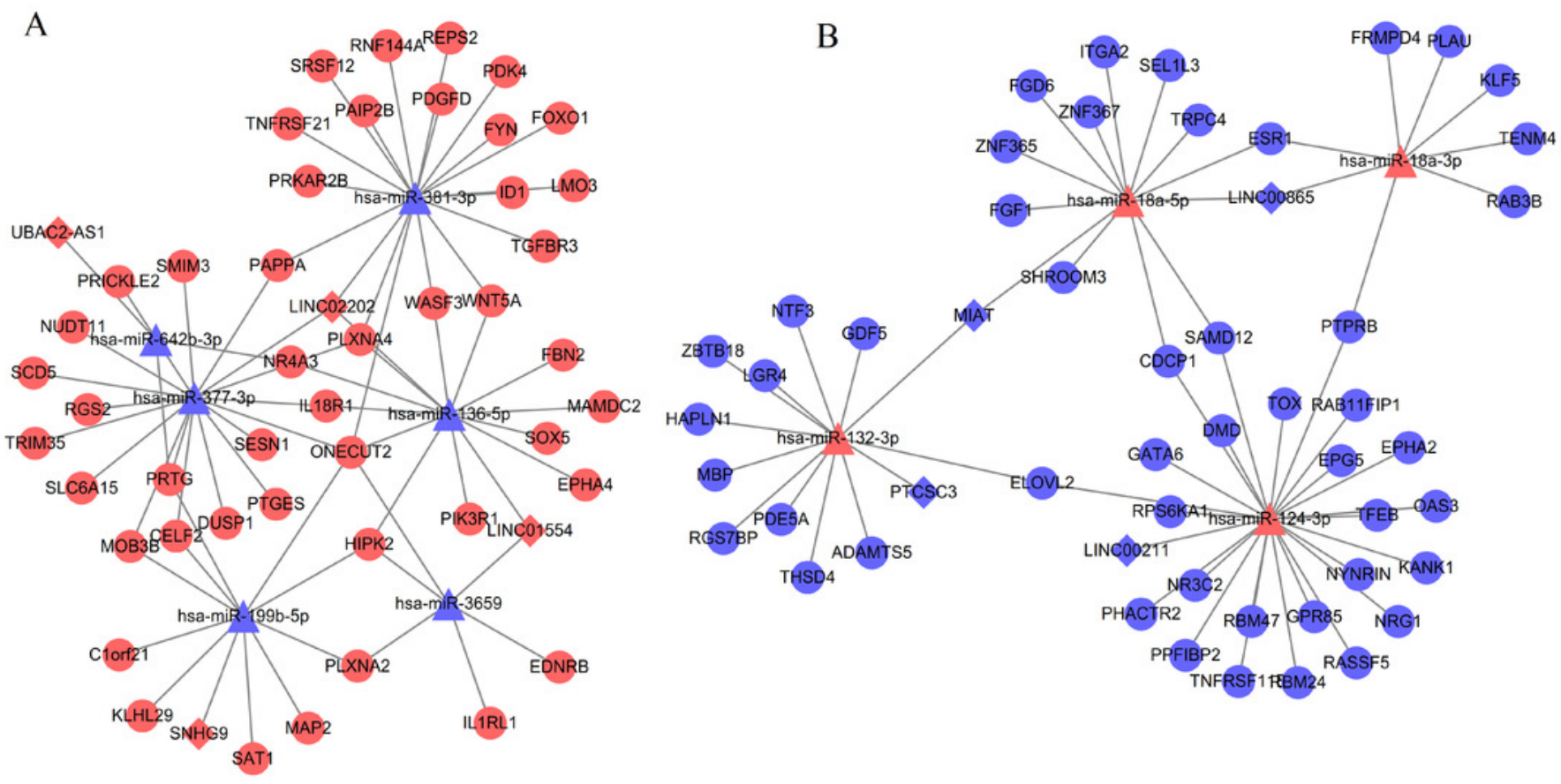
Figure 4

Protein-protein interaction network. Red, upregulated; Blue, downregulated. Oval, differentially expressed genes; hexagon, differentially expressed transcription factor.

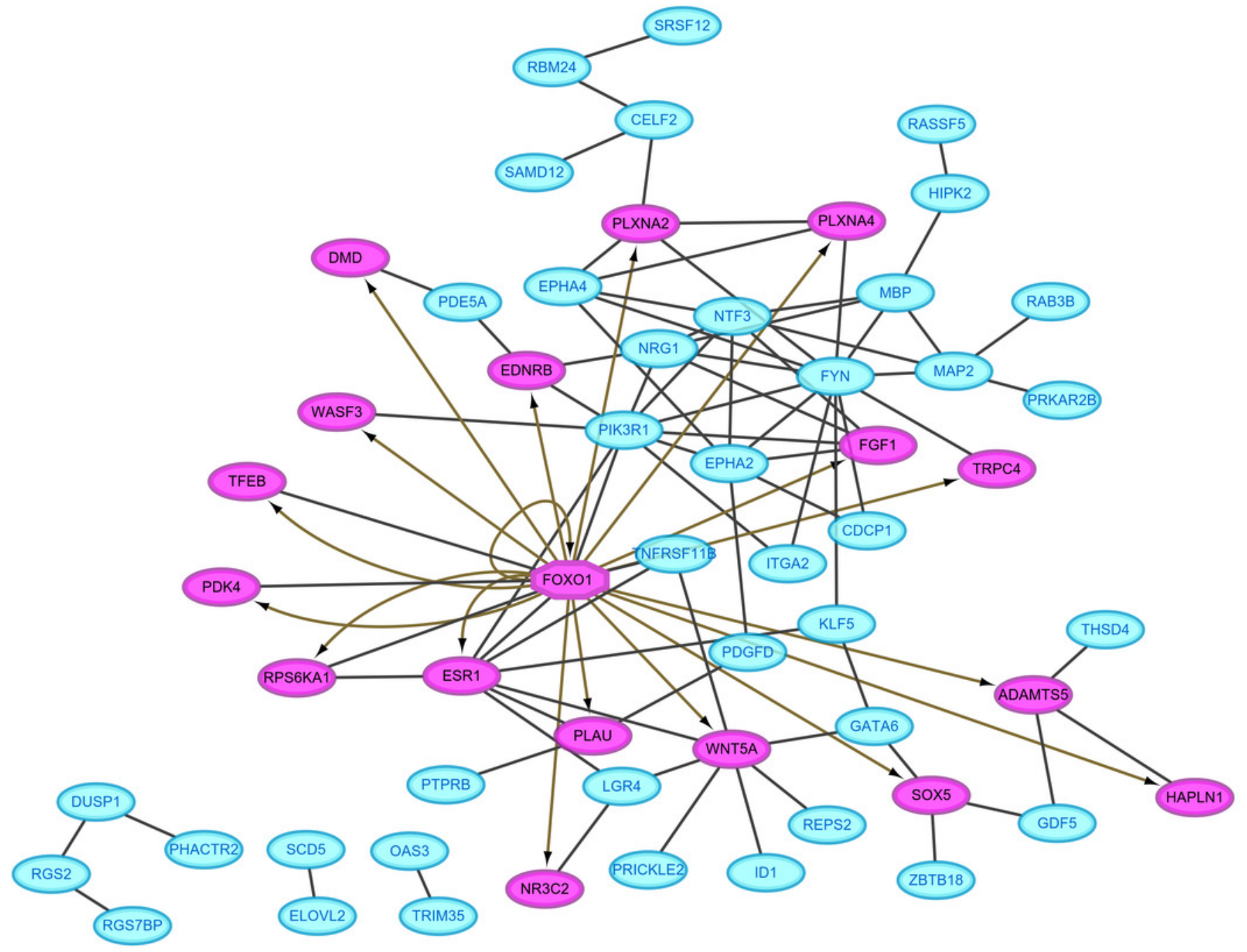




\section{Table $\mathbf{1}$ (on next page)}

Differentially expressed genes, IncRNAs and miRNAs

All the differentially expressed miRNAs and IncRNAs were shown, but only top 25 upregulated and downregulated mRNAs as well as crucial genes were displayed. FC, fold change. P-value with asterisk indicated their adjusted p-value were also less than 0.05 . 
Table 1 Differentially expressed genes, IncRNAs and miRNAs

\begin{tabular}{|c|c|c|c|c|c|c|c|c|}
\hline & $\log \mathrm{FC}$ & $\mathrm{P}$-value & & $\log \mathrm{FC}$ & $\mathrm{P}$-value & & $\log \mathrm{FC}$ & $\mathrm{P}$-value \\
\hline CRLF1 & 5.31 & $1.55 \mathrm{E}-10^{*}$ & SH3RF3-AS1 & 4.00 & $8.45 \mathrm{E}-06^{*}$ & miR-663 & 6.22 & $2.53 \mathrm{E}-06^{*}$ \\
\hline ZBTB16 & 6.71 & $2.90 \mathrm{E}-10^{*}$ & LINC01554 & 2.06 & $1.19 \mathrm{E}-02$ & miR-3607-3p & 5.55 & $3.91 \mathrm{E}-06^{*}$ \\
\hline COMP & 6.30 & $5.07 \mathrm{E}-10^{*}$ & SNHG9 & 2.04 & $1.45 \mathrm{E}-02$ & $\operatorname{miR}-455-3 p$ & 2.93 & $2.91 \mathrm{E}-04$ \\
\hline FOXO1 & 4.98 & $3.85 \mathrm{E}-09 *$ & LINC01914 & 2.35 & $1.74 \mathrm{E}-02$ & $\operatorname{miR}-455-5 p$ & 5.68 & $6.45 \mathrm{E}-03$ \\
\hline LMO3 & 4.92 & $5.15 \mathrm{E}-09 *$ & C18orf65 & 1.61 & $2.40 \mathrm{E}-02$ & $\mathrm{miR}-30 \mathrm{c}$ & 1.45 & $7.52 \mathrm{E}-03$ \\
\hline KLF15 & 5.19 & $6.31 \mathrm{E}-09^{*}$ & LINC02202 & 1.65 & $4.06 \mathrm{E}-02$ & miR-181b & 1.45 & $1.26 \mathrm{E}-02$ \\
\hline MT1G & 4.71 & $1.68 \mathrm{E}-08^{*}$ & UBAC2-AS1 & 1.69 & 4.17E-02 & miR-92a & 1.33 & $1.33 \mathrm{E}-02$ \\
\hline NEFL & 5.50 & $3.12 \mathrm{E}-08^{*}$ & LOH12CR2 & 1.86 & $4.55 \mathrm{E}-02$ & miR-609 & 2.43 & $2.97 \mathrm{E}-02$ \\
\hline NRCAM & 4.84 & $5.19 \mathrm{E}-08^{*}$ & OSER1-DT & 1.92 & 4.99E-02 & miR-339-3p & 2.48 & $2.99 \mathrm{E}-02$ \\
\hline PCSK1 & 4.32 & $1.05 \mathrm{E}-07 *$ & LINC01119 & -3.77 & $1.80 \mathrm{E}-04 *$ & miR-887 & 2.65 & $3.07 \mathrm{E}-02$ \\
\hline FRAS1 & 6.29 & $1.14 \mathrm{E}-07^{*}$ & SERPINB9P1 & -2.35 & $4.55 \mathrm{E}-03$ & miR-124 & 2.70 & $3.10 \mathrm{E}-02$ \\
\hline PDK4 & 5.95 & $1.50 \mathrm{E}-07^{*}$ & MIAT & -3.24 & $5.06 \mathrm{E}-03$ & $\operatorname{miR}-3653$ & 1.01 & $3.17 \mathrm{E}-02$ \\
\hline PER1 & 3.90 & $3.26 \mathrm{E}-07 *$ & LINC00601 & -1.85 & $1.98 \mathrm{E}-02$ & miR-652 & 2.90 & $3.20 \mathrm{E}-02$ \\
\hline IL18R1 & 4.60 & $4.67 \mathrm{E}-07^{*}$ & LINC00211 & -1.48 & $3.31 \mathrm{E}-02$ & miR-769-5p & 2.91 & $3.21 \mathrm{E}-02$ \\
\hline MT1X & 3.60 & $4.76 \mathrm{E}-07 *$ & PTCSC3 & -1.72 & $3.81 \mathrm{E}-02$ & $\operatorname{miR}-18 \mathrm{a}$ & 3.08 & $3.30 \mathrm{E}-02$ \\
\hline MT1M & 3.82 & $4.86 \mathrm{E}-07^{*}$ & CYTOR & -1.49 & 4.63E-02 & $\operatorname{miR}-1290$ & 3.31 & $3.42 \mathrm{E}-02$ \\
\hline PDE4D & 4.06 & $1.03 \mathrm{E}-06^{*}$ & LINC00865 & -1.53 & 4.85E-02 & miR-1973 & 1.15 & $3.45 \mathrm{E}-02$ \\
\hline SERPINA3 & 4.91 & $1.61 \mathrm{E}-06^{*}$ & SH3RF3-AS1 & 4.00 & $8.45 \mathrm{E}-06^{*}$ & miR-30a* & 1.84 & $3.87 \mathrm{E}-02$ \\
\hline RASD1 & 4.46 & $1.68 \mathrm{E}-06^{*}$ & & & & miR-132 & 1.23 & $3.87 \mathrm{E}-02$ \\
\hline IL1RL1 & 5.91 & $1.71 \mathrm{E}-06^{*}$ & & & & $\operatorname{miR}-\mathrm{K} 12-5^{*}$ & 2.93 & $4.46 \mathrm{E}-02$ \\
\hline GALNT15 & 4.46 & $2.24 \mathrm{E}-06^{*}$ & & & & $\operatorname{miR}-150^{*}$ & -6.28 & $3.37 \mathrm{E}-07^{*}$ \\
\hline FKBP5 & 3.42 & $2.37 \mathrm{E}-06^{*}$ & & & & $\operatorname{miR}-4271$ & -6.29 & $1.43 \mathrm{E}-06^{*}$ \\
\hline ELOVL3 & 3.94 & $2.95 \mathrm{E}-06^{*}$ & & & & $\operatorname{miR}-371-5 p$ & -6.51 & $1.79 \mathrm{E}-06^{*}$ \\
\hline HSD11B1 & 3.63 & $3.39 \mathrm{E}-06^{*}$ & & & & miR-134 & -6.39 & $3.26 \mathrm{E}-06^{*}$ \\
\hline PIK3R1 & 2.42 & $5.88 \mathrm{E}-04$ & & & & $\operatorname{miR}-146 b-5 p$ & -5.32 & $4.43 \mathrm{E}-04$ \\
\hline ARNT2 & -5.34 & $3.01 \mathrm{E}-08^{*}$ & & & & miR-136 & -2.12 & $1.12 \mathrm{E}-03$ \\
\hline FGF9 & -4.24 & $2.78 \mathrm{E}-07 *$ & & & & $\operatorname{miR}-199 b-5 p$ & -2.81 & 4.17E-03 \\
\hline IL6 & -5.82 & $2.90 \mathrm{E}-07 *$ & & & & $\operatorname{miR}-29 b$ & -1.80 & $5.88 \mathrm{E}-03$ \\
\hline OXTR & -5.64 & $2.06 \mathrm{E}-06^{*}$ & & & & $\operatorname{miR}-376 b$ & -4.36 & $9.46 \mathrm{E}-03$ \\
\hline RTKN2 & -4.16 & $2.83 \mathrm{E}-06^{*}$ & & & & miR-130b & -1.33 & $1.20 \mathrm{E}-02$ \\
\hline PTPRB & -4.63 & $4.43 \mathrm{E}-06^{*}$ & & & & $\operatorname{miR}-218$ & -3.94 & $1.22 \mathrm{E}-02$ \\
\hline SHROOM3 & -3.37 & $7.27 \mathrm{E}-06^{*}$ & & & & $\operatorname{miR}-154^{*}$ & -4.42 & $1.25 \mathrm{E}-02$ \\
\hline RGS4 & -3.28 & $8.10 \mathrm{E}-06^{*}$ & & & & miR-381 & -1.11 & $1.31 \mathrm{E}-02$ \\
\hline ARHGEF28 & -3.39 & $1.08 \mathrm{E}-05^{*}$ & & & & miR-377 & -1.23 & $1.45 \mathrm{E}-02$ \\
\hline GPR68 & -3.67 & $1.46 \mathrm{E}-05^{*}$ & & & & miR-503 & -1.85 & $1.59 \mathrm{E}-02$ \\
\hline VCAM1 & -4.30 & $1.59 \mathrm{E}-05^{*}$ & & & & $\operatorname{miR}-337-5 p$ & -1.04 & $2.13 \mathrm{E}-02$ \\
\hline ATP8B1 & -3.51 & $1.80 \mathrm{E}-05^{*}$ & & & & miR-3132 & -1.24 & $2.18 \mathrm{E}-02$ \\
\hline CNIH3 & -3.42 & $2.61 \mathrm{E}-05^{*}$ & & & & $\operatorname{miR}-362-3 p$ & -3.63 & $2.18 \mathrm{E}-02$ \\
\hline ZSWIM4 & -3.17 & $2.67 \mathrm{E}-05^{*}$ & & & & miR-3659 & -1.28 & $2.23 \mathrm{E}-02$ \\
\hline
\end{tabular}




\begin{tabular}{cccccc} 
EPHA2 & -3.36 & $3.35 \mathrm{E}-05^{*}$ & miR-H6 & -1.49 & $2.31 \mathrm{E}-02$ \\
CDCP1 & -4.48 & $3.93 \mathrm{E}-05^{*}$ & miR-135a* & -2.56 & $2.37 \mathrm{E}-02$ \\
FRMD5 & -3.14 & $4.35 \mathrm{E}-05^{*}$ & miR-29b-1* & -1.79 & $2.61 \mathrm{E}-02$ \\
NR3C2 & -2.88 & $4.40 \mathrm{E}-05^{*}$ & miR-376c & -1.09 & $2.64 \mathrm{E}-02$ \\
GREM2 & -3.48 & $4.91 \mathrm{E}-05^{*}$ & miR-193a-3p & -1.35 & $2.79 \mathrm{E}-02$ \\
CEMIP & -4.84 & $4.92 \mathrm{E}-05^{*}$ & miR-140-3p & -1.07 & $2.84 \mathrm{E}-02$ \\
BIRC3 & -3.21 & $8.05 \mathrm{E}-05^{*}$ & miR-642b & -3.77 & $3.04 \mathrm{E}-02$ \\
RBM24 & -3.28 & $9.30 \mathrm{E}-05^{*}$ & miR-125a-3p & -1.20 & $3.16 \mathrm{E}-02$ \\
KY & -3.20 & $1.08 \mathrm{E}-04^{*}$ & miR-140-5p & -1.26 & $3.51 \mathrm{E}-02$ \\
NUAK2 & -2.93 & $1.21 \mathrm{E}-04^{*}$ & miR-718 & -2.64 & $4.41 \mathrm{E}-02$ \\
FGF1 & -4.52 & $1.27 \mathrm{E}-04^{*}$ & miR-299-3p & -4.10 & $4.83 \mathrm{E}-02$ \\
ESR1 & -1.911 & $1.48 \mathrm{E}-02$ & miR-376a* & -4.02 & $4.99 \mathrm{E}-02$ \\
\hline
\end{tabular}

2 All the differentially expressed miRNAs and lncRNAs were shown, but only top 25 upregulated and downregulated mRNAs as 3 well as crucial genes were displayed. FC, fold change. P-value with asterisk indicated their adjusted p-value were also less than 4 0.05 . 
Table 2 (on next page)

Hub genes in the protein-protein network screened by topological features 
1 Table 2 Hub genes in the protein-protein network screened by topological features

\begin{tabular}{cccccccc}
\hline Gene & Degree & \multicolumn{3}{c}{ Betweenness } & \multicolumn{2}{c}{ Closeness } & Eigenvector \\
\hline FYN & 12 & FYN & 983.10 & FYN & 0.096 & FYN & 0.42 \\
PIK3R1 & 10 & PIK3R1 & 716.77 & PIK3R1 & 0.096 & PIK3R1 & 0.39 \\
ESR1 & 8 & ESR1 & 658.76 & KLF5 & 0.095 & NTF3 & 0.33 \\
NTF3 & 7 & GATA6 & 543.73 & ESR1 & 0.095 & EPHA2 & 0.32 \\
EPHA2 & 7 & KLF5 & 529.64 & EPHA2 & 0.093 & NRG1 & 0.30 \\
WNT5A & 7 & SOX5 & 438 & NRG1 & 0.093 & EPHA4 & 0.24 \\
NRG1 & 6 & WNT5A & 405.05 & FOXO1 & 0.092 & FGF1 & 0.24 \\
FOXO1 & 6 & PLXNA2 & 352 & NTF3 & 0.092 & MBP & 0.22 \\
EPHA4 & 5 & CELF2 & 274 & ITGA2 & 0.092 & MAP2 & 0.18 \\
MBP & 5 & GDF5 & 270 & GATA6 & 0.091 & ESR1 & 0.15 \\
\hline
\end{tabular}

2 


\section{Table 3 (on next page)}

KEGG pathway enrichment for the genes in the PPI network. 
1 Table 3 KEGG pathway enrichment for the genes in the PPI network

\begin{tabular}{llll}
\hline Term & P-value & Genes \\
\hline hsa04015:Rap1 signaling pathway & $2.25 \mathrm{E}-03$ & RASSF5, ID1, PDGFD, FGF1, \\
& & PIK3R1, EPHA2 \\
hsa05200:Pathways in cancer & $7.28 \mathrm{E}-03$ & $\begin{array}{l}\text { WNT5A, EDNRB, RASSF5, } \\
\end{array}$ & FOXO1, ITGA2, FGF1, PIK3R1 \\
& & WNT5A, ESR1, ITGA2, \\
hsa05205:Proteoglycans in cancer & $1.18 \mathrm{E}-02$ & PIK3R1, PLAU \\
& & RASSF, PDGFD, FGF1, \\
hsa04014:Ras signaling pathway & $1.78 \mathrm{E}-02$ & PIK3R1, EPHA2 \\
& & EPHA4, FYN, PLXNA2, \\
hsa04360:Axon guidance & $1.90 \mathrm{E}-02$ & EPHA2 \\
& & WNT5A, ID1, GDF5, FGF1 \\
hsa04390:Hippo signaling pathway & $2.97 \mathrm{E}-02$ & PTPRB, WASF3, FYN \\
hsa04520:Adherens junction & $4.03 \mathrm{E}-02$ & PDGFD, FGF1, PIK3R1 \\
hsa05218:Melanoma & $4.03 \mathrm{E}-02$ &
\end{tabular}




\section{Table 4 (on next page)}

GO biological process term enrichment for the genes in the PPI network 
1 Table 4 GO biological process term enrichment for the genes in the PPI network

\begin{tabular}{|c|c|c|}
\hline Term & P-value & Genes \\
\hline $\begin{array}{l}\text { GO:0042981 regulation of apoptotic } \\
\text { process }\end{array}$ & $6.04 \mathrm{E}-05$ & $\begin{array}{l}\text { RASSF5, TNFRSF11B, } \\
\text { DUSP1, NTF3, FYN, } \\
\text { GDF5, ESR1 }\end{array}$ \\
\hline $\begin{array}{l}\text { GO:0032148 activation of protein kinase } \\
\text { B activity }\end{array}$ & $7.76 \mathrm{E}-05$ & $\begin{array}{l}\text { WNT5A, NTF3, FGF1, } \\
\text { NRG1 }\end{array}$ \\
\hline GO:0007596 blood coagulation & $3.06 \mathrm{E}-04$ & $\begin{array}{l}\text { PRKAR2B, FYN, GATA6, } \\
\text { ITGA2, PDGFD, PLAU }\end{array}$ \\
\hline $\begin{array}{l}\text { GO:0071560 cellular response to } \\
\text { transforming growth factor beta stimulus }\end{array}$ & $5.22 \mathrm{E}-04$ & $\begin{array}{l}\text { WNT5A, FYN, SOX5, } \\
\text { PDGFD }\end{array}$ \\
\hline $\begin{array}{ll}\text { GO:0043066 negative } & \text { regulation of } \\
\text { apoptotic process } & \end{array}$ & $6.03 \mathrm{E}-04$ & $\begin{array}{l}\text { WNT5A, EDNRB, DUSP1, } \\
\text { RPS6KA1, ID1, GATA6, } \\
\text { FOXO1, PIK3R1 }\end{array}$ \\
\hline $\begin{array}{lll}\text { GO:0045944 positive regulation of } & \text { of } \\
\text { transcription from RNA polymerase } & \text { II } \\
\text { promoter } & & \end{array}$ & $1.01 \mathrm{E}-03$ & $\begin{array}{l}\text { KLF5, } \\
\text { RPS6KA1, } \\
\text { HIPK2, TFEB, } \\
\text { FOXO1, FSA, } \\
\text { PIK3R1 }\end{array}$ \\
\hline $\begin{array}{l}\text { GO:0045893 positive regulation } \\
\text { transcription, DNA-templated }\end{array}$ & $1.25 \mathrm{E}-03$ & $\begin{array}{l}\text { KLF5, WNT5A, GATA6, } \\
\text { HIPK2, TFEB, ESR1, } \\
\text { FOXO1, LGR4 }\end{array}$ \\
\hline $\begin{array}{l}\text { GO:0018108 peptidyl-tyrosine } \\
\text { phosphorylation }\end{array}$ & $1.47 \mathrm{E}-03$ & $\begin{array}{l}\text { EPHA4, FYN, } \\
\text { NRG1, EPHA2 }\end{array}$ \\
\hline $\begin{array}{ll}\text { GO:0014066 regulation } & \text { of } \\
\text { phosphatidylinositol 3-kinase signaling } & \end{array}$ & $2.02 \mathrm{E}-03$ & $\begin{array}{l}\text { FYN, } \\
\text { PIK3R1 }\end{array}$ \\
\hline $\begin{array}{l}\text { GO:0030335 positive regulation of cell } \\
\text { migration }\end{array}$ & $2.88 \mathrm{E}-03$ & $\begin{array}{l}\text { NTF3, PDGFD, } \\
\text { PIK3R1, PLAU }\end{array}$ \\
\hline $\begin{array}{l}\text { GO:0046854 phosphatidylinositol } \\
\text { phosphorylation }\end{array}$ & $3.43 \mathrm{E}-03$ & $\begin{array}{l}\text { FYN, FGF1, } \\
\text { PIK3R1 }\end{array}$ \\
\hline GO:0030182 neuron differentiation & $3.53 \mathrm{E}-03$ & $\begin{array}{l}\text { WNT5A, ID1, HIP } \\
\text { EPHA2 }\end{array}$ \\
\hline $\begin{array}{l}\text { GO:0008284 positive regulation of cell } \\
\text { proliferation }\end{array}$ & $3.70 \mathrm{E}-03$ & $\begin{array}{lrl}\text { KLF5, } & \text { EDNRB, } & \text { NTF3, } \\
\text { HIPK2, } & \text { PDGFD, } & \text { FGF1, } \\
\text { NRG1 } & \end{array}$ \\
\hline $\begin{array}{l}\text { GO:0048015 phosphatidylinositol- } \\
\text { mediated signaling }\end{array}$ & $4.80 \mathrm{E}-03$ & $\begin{array}{l}\text { FYN, FGF1, } \\
\text { PIK3R1 }\end{array}$ \\
\hline GO:0000187 activation of MAPK activity & 4.93E-03 & $\begin{array}{l}\text { WNT5A, NTF3, FGF1, } \\
\text { NRG1 }\end{array}$ \\
\hline $\begin{array}{l}\text { GO:0045892 negative regulation } \\
\text { transcription, DNA-templated }\end{array}$ & $5.16 \mathrm{E}-03$ & $\begin{array}{l}\text { WNT5A, ID1, GATA6, } \\
\text { FOXO1, NRG1, ZBTB18, }\end{array}$ \\
\hline
\end{tabular}




\begin{tabular}{|c|c|c|}
\hline & & LGR4 \\
\hline $\begin{array}{l}\text { GO:0045766 positive regulation of } \\
\text { angiogenesis }\end{array}$ & $6.02 \mathrm{E}-03$ & $\begin{array}{l}\text { WNT5A, GATA6, HIPK2, } \\
\text { FGF1 }\end{array}$ \\
\hline $\begin{array}{l}\text { GO:0000122 negative regulation } \\
\text { transcription from RNA polymerase } \\
\text { promoter }\end{array}$ & 7.94E-03 & $\begin{array}{l}\text { KLF5, EDNRB, ID1, } \\
\text { GATA6, HIPK2, ESR1, } \\
\text { FOXO1, ZBTB18 }\end{array}$ \\
\hline $\begin{array}{l}\text { GO:0043524 negative regulation of } \\
\text { neuron apoptotic process }\end{array}$ & 8.79E-03 & NTF3, FYN, GDF5, HIPK2 \\
\hline $\begin{array}{l}\text { GO:0035556 intracellular signal } \\
\text { transduction }\end{array}$ & 9.37E-03 & $\begin{array}{l}\text { PRKAR2B, RASSF5, } \\
\text { DUSP1, RPS6KA1, FYN, } \\
\text { NRG1 }\end{array}$ \\
\hline $\begin{array}{l}\text { GO:0045213 neurotransmitter receptor } \\
\text { metabolic process }\end{array}$ & $9.62 \mathrm{E}-03$ & DMD, NRG1 \\
\hline $\begin{array}{l}\text { GO:0060750 epithelial cell proliferation } \\
\text { involved in mammary gland duct } \\
\text { elongation }\end{array}$ & $1.28 \mathrm{E}-02$ & WNT5A, ESR1 \\
\hline $\begin{array}{l}\text { GO:0048146 positive regulation of } \\
\text { fibroblast proliferation }\end{array}$ & $1.31 \mathrm{E}-02$ & WNT5A, ESR1, PDGFD \\
\hline $\begin{array}{l}\text { GO:0043406 positive regulation of MAP } \\
\text { kinase activity }\end{array}$ & $1.54 \mathrm{E}-02$ & PDE5A, PDGFD, FGF1 \\
\hline GO:0043627 response to estrogen & $1.86 \mathrm{E}-02$ & $\begin{array}{l}\text { TNFRSF11B, } \\
\text { ESR1 }\end{array}$ \\
\hline $\begin{array}{l}\text { GO:0014068 positive regulation of } \\
\text { phosphatidylinositol 3-kinase signaling }\end{array}$ & $1.86 \mathrm{E}-02$ & FYN, PDGFD, NRG1 \\
\hline $\begin{array}{l}\text { GO:0048841 regulation of axon extension } \\
\text { involved in axon guidance }\end{array}$ & $2.23 \mathrm{E}-02$ & PLXNA4, PLXNA2 \\
\hline GO:0008366 axon ensheathment & $2.23 \mathrm{E}-02$ & NRG1, MBP \\
\hline $\begin{array}{l}\text { GO:0050966 detection of mechanical } \\
\text { stimulus involved in sensory perception of } \\
\text { pain }\end{array}$ & $2.54 \mathrm{E}-02$ & FYN, ITGA2 \\
\hline $\begin{array}{l}\text { GO:0008286 insulin receptor signaling } \\
\text { pathway }\end{array}$ & $2.61 \mathrm{E}-02$ & PDK4, FOXO1, PIK3R1 \\
\hline $\begin{array}{l}\text { GO:0090630 activation of GTPase } \\
\text { activity }\end{array}$ & 2.67E-02 & WNT5A, NTF3, EPHA2 \\
\hline GO:0060068 vagina development & 2.89E-02 & WNT5A, ESR1 \\
\hline $\begin{array}{l}\text { GO:0021785 branchiomotor neuron axon } \\
\text { guidance }\end{array}$ & $2.86 \mathrm{E}-02$ & PLXNA4, PLXNA2 \\
\hline GO:0007165 signal transduction & $3.11 \mathrm{E}-02$ & $\begin{array}{l}\text { TNFRSF11B, } \\
\text { RPS6KA1, } \\
\text { NR3C2, EDE53, } \\
\text { PIK3R1, PLAU }\end{array}$ \\
\hline
\end{tabular}




\begin{tabular}{|c|c|c|}
\hline $\begin{array}{l}\text { GO:0048013 ephrin receptor signaling } \\
\text { pathway }\end{array}$ & $3.12 \mathrm{E}-02$ & EPHA4, FYN, EPHA2 \\
\hline $\begin{array}{l}\text { GO:0031643 positive regulation of } \\
\text { myelination }\end{array}$ & $3.17 \mathrm{E}-02$ & WASF3, NRG1 \\
\hline $\begin{array}{l}\text { GO:0010976 positive regulation of } \\
\text { neuron projection development }\end{array}$ & $3.33 \mathrm{E}-02$ & WNT5A, FYN, DMD \\
\hline GO:1901653 cellular response to peptide & $3.48 \mathrm{E}-02$ & KLF5, ID1 \\
\hline GO:0046849 bone remodeling & $3.48 \mathrm{E}-02$ & LGR4, EPHA2 \\
\hline $\begin{array}{l}\text { GO:0033628 regulation of cell adhesion } \\
\text { mediated by integrin }\end{array}$ & $3.48 \mathrm{E}-02$ & EPHA2, PLAU \\
\hline GO:0001525 angiogenesis & $3.49 \mathrm{E}-02$ & KLF5, PTPRB, ID1, FGF1 \\
\hline $\begin{array}{l}\text { GO:0007179 transforming growth factor } \\
\text { beta receptor signaling pathway }\end{array}$ & $3.53 \mathrm{E}-02$ & ID1, GDF5, HIPK2 \\
\hline GO:0008584 male gonad development & $3.68 \mathrm{E}-02$ & WNT5A, GATA6, ESR1 \\
\hline $\begin{array}{l}\text { GO:1902287 semaphorin-plexin signaling } \\
\text { pathway involved in axon guidance }\end{array}$ & $3.79 \mathrm{E}-02$ & PLXNA4, PLXNA2 \\
\hline GO:0055119 relaxation of cardiac muscle & $3.79 \mathrm{E}-02$ & RGS2, PDE5A \\
\hline $\begin{array}{l}\text { GO:0007169 transmembrane receptor } \\
\text { protein tyrosine kinase signaling pathway }\end{array}$ & $3.82 \mathrm{E}-02$ & NTF3, FYN, NRG1 \\
\hline GO:0001678 cellular glucose homeostasis & $4.41 \mathrm{E}-02$ & FOXO1, PIK3R1 \\
\hline GO:0060065 uterus development & $4.41 \mathrm{E}-02$ & WNT5A, ESR1 \\
\hline $\begin{array}{l}\text { GO:0006636 unsaturated fatty acid } \\
\text { biosynthetic process }\end{array}$ & $4.72 \mathrm{E}-02$ & ELOVL2, SCD5 \\
\hline
\end{tabular}

